\title{
Research on SysML-Based Urban-village Security Administration System
}

\author{
Zhu Xiaoning ${ }^{l}$ \\ School of Political Science and Public Administration, \\ University of Electronic Science and Technology of China, \\ Chengdu, P.R.China, 611731
}

\author{
Han Jiasheng ${ }^{3}$ \\ School of Mechatronics Engineering, University of \\ Electronic Science and Technology of China, Chengdu, \\ P.R.China, 611731
}

\author{
Yang Liwei ${ }^{2}$ \\ School of Political Science and Public Administration, \\ University of Electronic Science and Technology of China, \\ Chengdu, P.R.China,611731 \\ ylwei2010@163.com
}

\begin{abstract}
Urban-village is a special and widespread phenomenon which has been resulted from urban-rural dual structure. Urban-village security problem is the major difficulty for urban governance. As the reconstruction of Urban-village can't be accomplished in one-time action, Urban-village security problems will exist over a period of time. Based on new public service theory and system management thought, this paper is trying to find out a mode of Urban-village security administration by building a security administration model. The purpose of the research is to guarantee safety requirements of Urban-village residents and maintain long-term stability of the city.
\end{abstract}

Keywords-Security Administration, Urban-village, SysML, System Modeling

\section{System Management Thought and SysML}

System management thought is a thought which applies general systems theory to organization management. The aim is to use systems research methods and tools to build a common model and solve problems from management areas. System management thought considers the administration object as an ecosystem and analyses the sub-systems and elements. It can effectively avoid the disjoint management. That's why it is extensively used by many researchers to solve problems in government administration and public services. With the in-depth study of the system, a new system modeling language SysML has emerged. It is the methodological innovation under the guidance of system management idea. SysML includes the two parts of semantical representation. SysML defines the semantics of the system structure model, behavior model, and demand model parameter model. Meanwhile it achieves visual representation for semantic by showing various aspects of the model through class diagrams, assembly diagrams, Parametric diagrams, requirements diagrams, activity diagrams, sequence diagrams, time diagrams, state charts and use case diagrams nine basic graphics. As a standard multi-purpose modeling language, SysML supports a detailed description of explanation, analysis, design, verification and validation of various complex systems so that it can be extensively applied to various fields.
It is able to methodically decomposing the complex public service systems by using SysML modeling techniques. On the structural model level, it using class diagrams, assembly drawings defines the administration participants and their relationship. On the behavioral model level, using activity diagrams, sequence diagrams, time diagrams clarify the process and optimize the working flow. On the demand model level, using requirements diagrams achieves demand oriented analysis. On the parameters model level, combined with parametric diagrams, achieves qualitative and quantitative combining research and even promotes public service procedures under certain conditions. This is both modeling techniques and a way of thinking. Since the issue of public services becomes increasingly complex, SysML-based research can better solve related problems by building management models.

\section{The Raising of Urban-VIllage Security Problem}

\section{A. Formation and Characteristics of Urban-village}

With the deepening of reform and the promotion of urbanization, in the process of rapid development of the city, a special urban residential area appears, which is composed of peasants who still live in their original village since their arable land has been acquired and their personal identity change to be townsfolk. On the surface, these villages have achieved the transformation of the city. However, the ideology, habits and self-organization of the population of this part have not changed and retain the characteristics of rural areas. As an urban and rural blend area, these villages present a certain transitional state in the population, social structure and economic development, showing a "non-city and non-village" scene. So Urban-village is a residential area with low living standard, lagged behind the development of the times and isolated from modern urban management. Urban-village is a result of the latest urbanism problem due to incomplete urbanization. Caught in the urban and rural areas, Urbanvillage has the following four characteristics. (1)Disorder of construction. It means the construction of the buildings in the community is under morphological disorder and anarchism being not subject to rules of the overall planning of the city. 
(2)The complexity of the inhabitants. That is to say the composition of the inhabitants is complicated and their highfrequency mobility. (3) "Duality" of Administration system. On the one hand, Urban-village shows traces of urban administration, on the other hand, it retains rural management mode to a large extent. (4) Incompleteness of Infrastructure. Due to urban-rural dual structure, the municipal facilities of Urban-village are not complete and the social security mechanism is not perfect, which result in social risks ${ }^{[2]}$.

\section{B. Urban-village Security Problem and Its Causes}

In the process of rapid urbanization, Urban-village is subject to the interaction and interpenetration of cities, villages and other exotic ingredients. It obviously shows the complexity of the population, economy and management. Various social problems generated from time to time, especially security problems. Urban-village is a breeding bed for different kinds of crime and an area of high incidence of urban crime. It is not conducive to Urban-village internal management and it also set the security and social risks for the development of the entire city. The reasons for Urban-village security problems are as follows. Firstly, Urban-village is a place where the internal environment is complex, its infrastructure is poor and has many factors of instability. The original inhabitants used to living on agriculture and did not have a high-level education. During the transformation to townsfolk, they lost arable land and meanwhile have not got the capability to survive in the city. Mentally stricken by the significant gap between richness and poverty, they are likely to be induced to commit a crime and go astray. Secondly, Urban-village is also a high-frequency mobility zone. The constitution of the local population here is complex, which leads to difficult File Management. Once a security incidence happens, the police could hardly identify the illegal offenders. This becomes a legal loophole that criminals can take advantage of. Thirdly, due to the urban-rural dual management structure, functional departments are disconnected and emergency interaction is not available. Once security problems have become security incidence, it is hard to control the situation. In conclusion, the root cause of Urban-village security problem is the urban and rural dual structure. The fundamental reason is that the security management mechanism is not fully in place. The direct reason is the complexity and instability of Urban-village internal environment ${ }^{[3]}$. Urban-village security problems have a serious influence on the daily life of its residents, and even go against the harmony and stability of the whole society.

\section{FeAsibILITy OF SysML-BASED URBAN-VILLAGE SECURITY SYSTEM STUDY}

\section{A. Systematicness}

The introduction of SysML into the study of Urban-village security management System is to build an administrative model of Urban-village security system by means of designing a security administration framework based on the semantics of SysML and using SysML notation. Use request model to analyze the requirements of Urban-village public security services at the present stage so as to determine the main contents of Urban-village security management under modern governance. Use behavioral model to rationalize the relationship between security management, the prevention and control of public security and emergency interaction, regarding them as three subsystems of security management system. Finally, use structural model to integrate the internal elements of each subsystems, straighten out their relationship and promote the organic coordination among them. By introducing SysML, a huge security management system can be separated into subsystem module, which makes it possible to systematically set a few lines for the contents of fragmented and trivial security management according to the needs, structure and behavior. This provides a theoretical feasibility of designing a framework and constructing a model of Urbanvillage security administration system.

\section{B. Comprehensiveness}

Based on SysML, this paper uses request analysis as its research starting point. It is a big change from the former political security control to social security services. From this research perspective, the design of Urban-village security administration system can better divide the functions of security administration, highlight the leading security administrator and optimize the involving way of each participant insecurity administration. In the meantime, it helps the government realize its role change from a regulator into a servant. Urban-village security issues are related to variant type of problems and each case shows different crux. Therefore, the advantage of SysML lies in that the function of its nine basic patterns is very powerful. Different graphics can be used for the scientifically modeling of different module so as to effectively avoid the limitation of single modeling and ensure the scientificness of Urban-village security administration system Modeling ${ }^{[4]}$.

\section{The Operation Mechanism of URban-VILLAGE SECURITY MANAGEMENT SYSTEM}

Urban-village security management is a complete system. Taking the resident needs analysis of Urban-village as the starting point of the research, It can be concluded that security management contain four aspects. They are prevention of security problems, defuse of potential crimes, handling of general cases as well as emergency response of severe security issues. Hence, it is necessary to establish and improve the management organizations in correspondence with the e four aspects. In specific, it shall include Community Integrated Management Agency, Security Problems Prevention-control Police Agency and Emergency Interaction Response Center ${ }^{[5]}$.

Firstly, the occurrence of security incidents should be prevented. This requires a comprehensive Urban-village community management agency to build a secure community environment and agreeable atmosphere a nice security through integrating community security resources, Strengthening study and promotion of legal rules and actively making use of external resources. Secondly, the Security Prevention-control Agency should carry out the registration administration of mobile population, supervision of emancipist and visiting of ordinary urban villager so that security risks and potential crime can be prevented beforehand. Meantime the police agency can also deal with common security problems by 
banning illegal operations and conducting security patrols. Finally, in case of occurrences which is likely to expand and hard to deal with, community police agency shall promptly release the information through early warning mechanism. That means when a common security problem changes to be a criminal case or a people gathering security event, through this early warning mechanism, community police agency is able to contact the emergency response center timely so that a special action team can be jointly set up in time by city public security and other authorities to conduct the intervention cooperatively. In most cases, it is difficult to get early warning in public safety affairs. So emergency response centers should streamline the process of handling security incidents, in case of no early warning emergency case happening and get fully prepared. Every security incident response and disposal methods should eventually feedback to the community policing and community integrated management center for the future accumulation of experience to carry out the work.

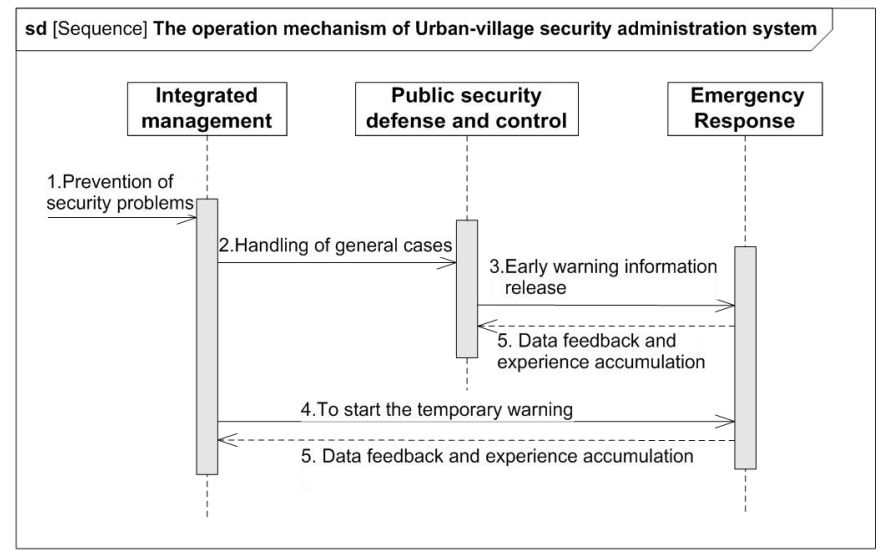

Fig.1. SysML Sequence Diagram of Operation Mechanism

In summary, the key to the operating of Urban-village security administration system is to change the hysteretic disposal measures of security problems in the past. That means it's necessary to do relevant work in advance, i.e. to build communication platform between the community and residents and police and residents as well, to Strengthen community services and social care, to alleviate social conflicts and disputes caused by rural dual structure, thus to avoid security problems and security incidents and create a secure environment for the Urban-village community residents as well as. provide good public safety services for them ${ }^{[6]}$.

\section{The Building of Urban-VILlage Security MANAGEMENT System Model}

\section{A. Requirements Analysis of Urban-village Security Administration}

Urban-village Security Administration requirements analysis needs to be mainly considered from the security needs of Urban-village residents. Surviving in the cracks of the city, on the one hand, these residents rely on the physical safety of life, health and property. On the other hand, they rely more on psychological safeness. This psychological sense of safeness comes from the acceptance by urban society and integration of lifestyle. Thus the demands of the Urban-village security administration are as follows. Firstly, it's to ensure the psychological safety of Urban-village residents. Secondly, it's to maintain their physical safety ${ }^{[7]}$. Thus, the primary meaning of Urban-village Security management is to provide security services, followed by security management.

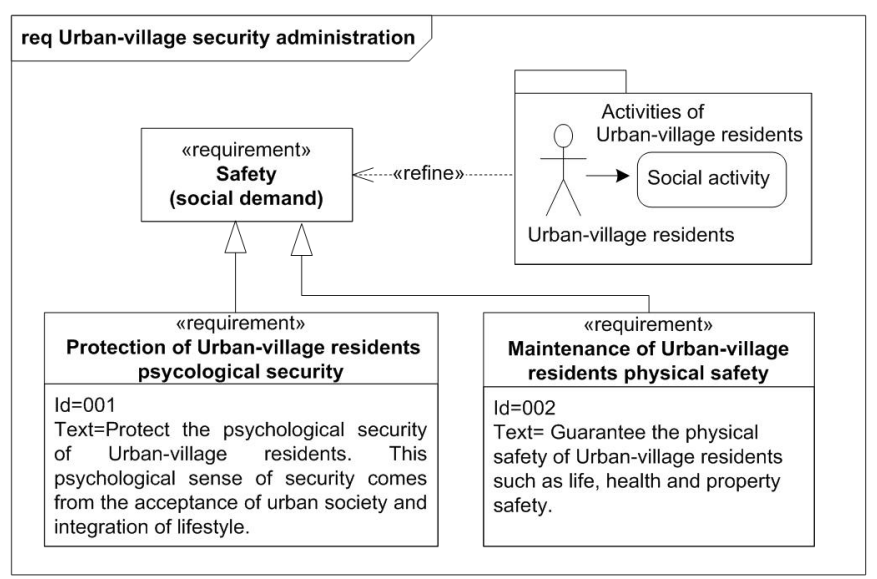

Fig.2. SysML Requirements Diagram of Urban-village Security Management

Figure 2 is a demand model of Urban-village security administration. As it shows, safeness as a top requirement can be defined as a blank requirement or that of an empty class, from which the specific Sub-requirements are derived from. Demand characterization is to guarantee the psychological security needs of Urban-village residents. Another demand characterization is to maintain their physical security needs. These two Sub-requirements are inherited from their parent requirements. In the diagram, the example of Urban-village residents participating in social activities is used as a model element. It is also a sub-requirement relying on social safety demand of $<<$ requirement $>>$.

\section{B. Architecture of Urban-village Security administration}

Figure 3, in the form of a class diagram, depicts the system architecture of Urban-village security management in the view of software engineering. The whole Urban-village security administration system as a parent class consists of the two properties of "demand" and "mechanism", from which are derived the three sub-classes of. Urban-village community integrated security management system, Urban-village security prevention police system and security emergency interaction response system. Since the parent class is composed of the subclasses and sub classes succeed the parent class property, the general relationship between parent class and sub-classes is the combination relation of 1 for $n$. The three subclasses are relatively independent from one another and interconnected as well, so their relationship is n-n association.

\section{1) Integrated Community Security Administration System}

In order to prevent Urban-village security problems, the key solution is to introduce community management and community services. To carry it out a Street Office shall take the lead to form an Integrated Community Security Administration agency composed of community residents committee, aboriginal autonomous organization and enterprises security department. This means to form an integration organization which includes government, community 
autonomy organizations, community enterprises and resident representatives to handle security problems, resolve conflicts and provide security needs service.

Firstly, it needs to have the internal resources of the Urbanvillage community integrated by working out a mass prevention and mass control system composed of community defense system, enterprises defense system and self-defensive system and setting up A multiple collaboration mechanism of community security management by rationally dividing the responsibilities of Urban-village community security management and establishing appropriate accountability mechanisms. To do this, it's necessary to build the integrated community security management information platform to provide a channel for information exchange, problems submission and requirements conveying. Through this way, it can be attained to optimize the allocation of Urban-village internal security resources and strengthen the mass foundation for Urban-village Security Administration. Secondly, it needs to improve the internal safe environment of Urban-village community by removing the potential dangerous elements which may cause Urban-village community security events. To achieve this, it's necessary to. take specific measures like cleaning up the street and installing anti-theft system, etc. to create the security atmosphere for the Urban-village community. Thirdly it needs to do a good job in security promotion and education. By having public columns and lectures on public security precautions in a people and mass oriented view, so as to ensure the lives and property safety of the residents are put in the first place. Fourthly, it needs to get external resources. This can be achieved through acquiring more external support including fund, charity help and voluntary service to carry out community security administration by contacting the third sector. Urban-village comprehensive community security agency shall put community security service in the first place. Its major function is to resolve social conflict and build a secure atmosphere of the community.

\section{2) Security Prevention and Control Police System}

To effectively prevent the Urban-village security problems from occurring, the core measure is to establish a Urban-village security prevention and control policing system. That is to establish a policing system with community prevention at the core by separating community police office from the agency. Firstly, controllable regulations in regard to targeted people shall be established in terms of Strict registration and management of mobile population; legal education of teenagers for them to correct their bad behaviors in a timely manner; as well as assistance and guide of emancipists. The classified and extended assistance and guide is very important to help emancipists not to be subject to discrimination and merge into the society once again. Secondly, potential crime prevention system shall be established by means of implementing the Urban-village community "Lighting Engineering", establishing security guard post, exerting guard patrol and security monitoring system to enforce community "Safe Living Engineering" and promoting the use of "home alarm" and other effective defense facilities, effectively enhance the capability of prevention, detection, control and combat for crimes. In the place where security danger exists, the police shall carry out scroll investigation and rectify security mess and striking problems. By supervision and control, to make sure leaders are in place and responsibilities taken. Thirdly, prompt police interaction response mechanism shall be formulated. With the establishment of "Five in One" police linkage mechanism consisting of the commission of neighborhood residents, police office, mobile people management station, coordination committee and real estate management station to promptly resolve common public security cases. Fourthly, the emergency pre-warning information platform shall be available, in order to promptly release pre-warning information in regard to after the study and judgement or classification of security incidents for their possible expansion.

\section{3) Emergency Interaction Response System}

To achieve Urban-village security governance, also we need to build Urban-village emergency response system as a potent guarantee which has an Emergency Response Center with public security, fire-fighting and medical care organizations as its core members. On receiving the prewarning information, event can be first disposed in time and by introducing science and technology early disposal, rapid assessment, joint coordination and scientific decision can be made. At the same time, recovery and caressing mechanism needs to be ready to restore the order of the community and caress the people. Finally, the data of every emergency security incident should be stored as to assess the handling process, gather experiences, and give feedback to the community and community police agency for them to carry out the training, promotion and demonstration of security precautions according to the emergency pre-action plan. By this way, to accumulate experiences for future work.

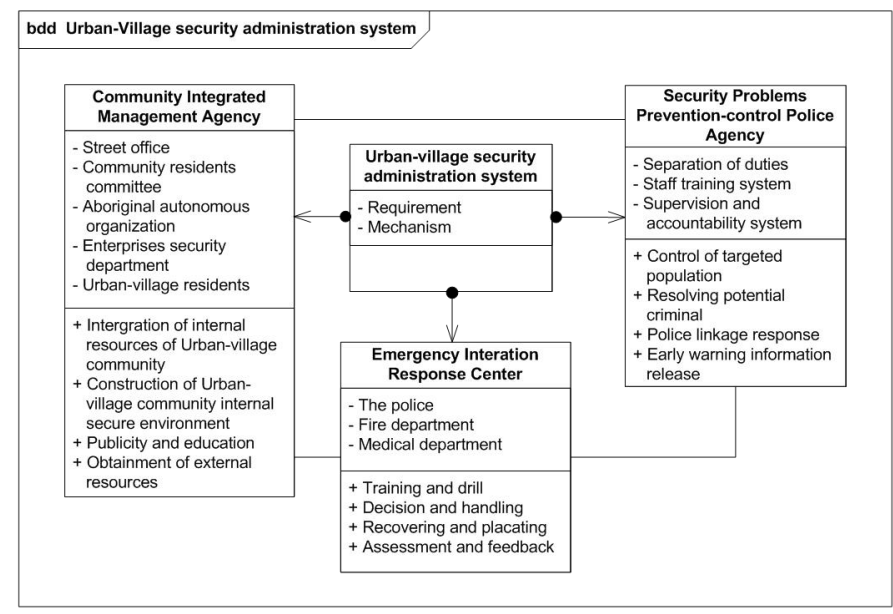

Fig.3. SysML Class Diagrams of Security Management System

\section{CONCLUSIONS}

Urban-village is an integrated security administration system that emphasizes both "community-centered" security management and security services and also stresses security control and prevention with "police system as the core". Strong "emergency interaction response mechanism" is an important support and foundation of Urban-village security administration. The direct means to solve the current Urbanvillage security issues is to rationalize the relationship between security management, security prevention and control as well 
as emergency response, so as to achieve the smooth operation of the three subsystems and strengthen the functions of community organizations and police system. Urban-village is a product of urban-rural dual structure. The Urban-village security Problems can be eradicated only by breaking urbanrural dual structure in order to maintain long-term stability of the city ${ }^{[8]}$.

\section{ACKNOWLEDGMENT}

This work is supported by the Complex Liberal Arts Laboratory of SPSPA and the Research on the Grid Mechanism of Public Service in the Context of Urban and Rural Areas (Grant No.09BZZ032).

\section{REFERENCES}

[1] Jiang Caiyun,Wang Weiping. SysML: A New Modeling Language[J]. Journal of System Simulation,2006 (18), pp.1483-1492(in Chinese)
[2] Yin Zhaonan. Research on the Prevention system of Urban-village Security[D]. Changjiang University,2014(in Chinese)

[3] Yuan Fang. The Study of Multi Central Governance Security Management of Urban Fringe Areas[J]. Zhongzhou Journal, 2011(3), pp.130-134(in Chinese)

[4] Liu Mingyu. The Innovation of Urban Security Administration Mechanism[J]. Mordern Economic Information, 2010(in Chinese)

[5] Zhang Jing. The Mechanism of Society Security Management and the System of Crime Prevention and Control in Japan[J]. Journal of Beijing Union University, 2015(7), pp.67-77(in Chinese)

[6] Gu Xiao. SysML-based Emergency Management System Modeling Technology[D]. Nanjing University of Science and Technology,2012(in Chinese).

[7] Peng Linhua. The Study on the Urban Community Security Management[D]. Xiangtan University,2012(in Chinese)

[8] Yu Yue. The neccessity of Urban-village Reform from the View of Urban-village Security Problems[J]. Theoritic Observation,2011(in Chinese)

[9] Gao Xuewu. Strategy of the Dilemma in Urban-village Governance from the View of Urbanization[J]. Macroeconomics,2014(in Chinese) 